\title{
Exploring HIV and AIDS Stigmatisation: Children's Perspectives
}

\author{
Gcina Kheswa \\ Department of Psychology, University of South Africa \\ Email: kheswge@unisa.ac.za
}

\section{Doi:10.5901/mjss.2014.v5n15p529}

\begin{abstract}
HIV and AIDS-related stigma has been recognised as one of the main obstacles to the prevention, care and treatment of HIV and AIDS. The aim of the research on which this article is based was to examine the experience to stigmatisation of a group of children whose parents have succumbed to AIDS or are living with HIV and AIDS. Semi-structured interviews were conducted with ten children between 13 and 16 years old who were volunteer counsellors and thus well-placed to describe the manifestation of stigma in their community]. Data were analysed through thematic content analysis. The findings show that stigmatisation remains a pervasive experience in the lives of the children of PLWHA. This article suggests that more research should be conducted on how HIV stigma affects the lives of children whose parents are affected by HIV and AIDS in South Africa.
\end{abstract}

\section{Introduction}

Research indicated that HIV and AIDS-related stigma has been recognised as one of the main obstacles to the prevention, care and treatment of HIV and AIDS (Ogden \& Nyblade, 2005). There are reasons behind obstacles to the prevention, including the people's reluctance to participate in the HIV and AIDS education and prevention activities (Herek \& Capitanio, 1999). Severe negative public reactions ranging from banning entry of HIV-infected individuals to isolating an individual in the family, deserting a pregnant woman upon knowing her HIV status in the hospital, or removing a person from his job, or even denying a child admission in a school (Mawar, Sahay, Pandit \& Mahajan, 2005) are some of the reasons for the reluctance to participate in HIV and AIDS prevention activities. Some researchers view stigma as too cultural, too context-specific, and too sensitive to be addressed meaningfully, thus making it difficult to design and implement interventions (Ogden \& Nyblade, 2005).

The aim of the research on which this article is based was to examine the exposure to stigmatisation of a group of children whose parents have succumbed to AIDS or are living with HIV and AIDS. This research could help to provide a supportive environment to assist children to deal with the effects of HIV and AIDS stigma (Germann, 2004; Morgan, 2000; Strode \& Grant, 2001).

\section{Background and Literature Review}

Stigma associated with HIV and AIDS has been present since the epidemic began (Avert 2010; Cluver \& Orkin 2009; Kheswa, 2006). In reviewing literature on the children affected and infected with HIV and AIDS associated with stigma, the following aspects are discussed: henceforth defining stigma (namely stigma, stigmatization, HIVIAIDS stigma, and children); stigmatisation and HIV and AIDS, a discussion on the dimensions of stigma; the different experiences of children on HIV and AIDS-stigma; and the prevention interventions.

\subsection{Defining stigma}

Stigma refers to the imposition of a special, discrediting and unwanted mark on a person or a specific category of persons in such a way that in their interactions with others, they are viewed by themselves and others as fundamentally and shamefully different (Strode \& Grant, 2001). Stigmatisation is defined as a social process by which people use shared social representations to distance themselves and their group from the risk of contracting a disease by: constructing it as preventable or controllable; identifying immoral behaviours causing the disease; associating these behaviours with carriers of the disease in other groups; and thus, blaming certain people for their own infection and justifying punitive action against them (Deacon, Stephney \& Prosalendis, 2005). 
AIDS-related stigma denotes the unfavourable attitudes, beliefs and policies directed toward people perceived to have HIV and AIDS as well as their children, social groups and communities (Department of Health and Human Administration, 2004). Children are defined as being persons under the age of eighteen years (Constitution of South Africa, in UNAIDS/WHO, 2004).

There has been an emerging interest in the impact of stigma on conditions such as mental illness, obesity, eating disorders, cancer, and HIVIAIDS. Several authors have already advocated that stigma is a multidimensional construct (Bresnahan and Zhuang, 2011; Herek et al., 2002; Link and Phelan, 2001, Swendeman et al. 2006). According to Bresnahan \& Zhuang (2011), there is still conceptual ambiguity and lack of consensus about the number of dimensions that make up the stigma construct. The next section discusses the different dimensions of stigmatization as discussed by different researchers.

\subsection{The dimensions of stigmatisation}

According to Bresnahan and Zhuang, (2011), stigma research is hampered by lack of consensus about the number of dimensions making up the stigma construct and what these dimensions measure. Mak, Cheung, Law, Woo, Li and Chung (2007) identified controllability, responsibility, blame, self-stigma, social support withdrawal, and psychological distancing as the six dimensions of stigma. Emlet (2005) also identified the following three dimensions of the stigma construct: distancing, blaming, and discrimination.

Deacon and Stephney (2007) also distinguish between types or dimensions of stigma, namely direct, indirect, secondary stigma, courtesy stigma and self-stigmatisation. Firstly, the direct effects of stigma lead to active discrimination or status loss. Secondly, the indirect effect entails the process whereby when caregivers suffer the effect of stigma or discrimination, or when children or parents take certain courses of action (such as withdrawal) to avoid expected stigma or discrimination. Thirdly, secondary stigma is defined as stigma attached to other things (such disease, objects and practices) because of their association with HIV and AIDS. Fourthly, courtesy stigma is stigma attached to people because of their association with HIV and AIDS or HIV-positive people, for example, stigmatisation of family members of a person identified as being infected with HIV and AIDS, or stigmatisation of healthcare workers who work with people living with HIV and AIDS. Lastly, self-stigmatisation is associated with stigmatised people's responses to stigma which include self-stigmatisation, for example, when PLWHA come to agree with the social perception of them as devalued, and perceived (Deacon \& Stephney, 2007).

The study by Herek et al., 1993 (in Kheswa 2006) suggests that stigmatisation varies along numerous dimensions, including the degree of disruptiveness, or aesthetic qualities, cause or origin, course or changes over time, the degree of peril held for others, and concealability. In addition, Crandall and Moriarty 1995 (in Kheswa 2006) hold that the disruptiveness dimension is clearly important in determining the extent to which a particular stigma interferes with a person's everyday life. Simbayi, Kalichman, Strebel, Cloete, Hendaa and Meketoa (2007) also identified four dimensions of stigma including internalized stigma, discrimination, cognitive and affective depression, and lack of social support. Puhl RM, Schwartz MB and Brownell KD (2005) also identified only one dimension of stigma - stereotyping - which they operationalized as negative and positive trait assignment. Lack of consensus about the number of dimensions making up the stigma poses significant barriers to prevention and treatment to stigmatized conditions.

\subsection{Stigmatisation and HIVIAIDS}

Various illnesses are associated with varying degrees of stigmatisation (Mason, Carlisle, Watkins \& Whitehead, 2001). Several studies have demonstrated the pervasive effects of stigmatisation on the lives of those with epilepsy (Bandstra $N$ F, Camfield, CS, \& Camfield PR. 2008), schizophrenia (Sibitz, Unger, Woppmann, Zidek, \& Amering, 2011) and Alzheimer's disease (Behuniak, 2011). Furthermore, researchers have consistently demonstrated that HIV and AIDS are stigmatising illnesses (Kinsler, Wong, Sayles, Davis\& Cunningham, 2007). They have argued that people living with HIV and AIDS and their support networks experience a particular and more intense type of stigmatisation than people with other medical conditions.

The AIDS stigma is manifested in a variety of ways. Survey research has shown that a significant minority of the US public harbours negative feelings toward people living with AIDS together with their children (Herek \& Capitanio, 1993). People living with AIDS have been more negatively evaluated than persons with other diseases, even by healthcare workers and mental health professionals (Crawford, Humfleet, Ribordy, Ho \& Vickers, 1991). 
Herek (1999) observed that people diagnosed with HIV are viewed more negatively than people diagnosed with other incurable diseases. He also noted that gay men and injection drug users are disproportionately susceptible to HIVrelated stigma and discrimination. According to Herek, HIV-related stigma is not necessarily a stigma of the diseased; rather, it is often related to perceived lifestyle "choices" of infected populations or to perceptions about racial and ethnic minorities.

Many research studies have found a significant number of respondents who want people living with HIV to be clearly identifiable, to be separated from the rest of the population, or excluded from contact in schools, works and social institutions (Strebel \& Perkel, 1991). Conflicting views surrounding people living with HIV are sometimes observed. For example, in a workplace study it was established that there was enormous compassion for colleagues who were HIVpositive, together with a wish to know who is HIV-positive, implying a need to keep separate from those who were infected (Miller \& Mastrantonis, 1992). It appears that knowing the person who is HIV- positive inspires greater feelings of compassion, but also a fear of the disease and the associated stigma remains.

Research also suggested that being associatively stigmatised may lead family and friends to distance themselves from the infected person (Crawford, 1996 in Kheswa, 2011). These reactions may even lead family members and friends to harbour resentment towards the infected person. Because they are concerned about being stigmatised by association, the family and friends of people with HIV and AIDS, and family caregivers in particular, often go to great lengths to keep the loved one's HIV status secret (Powell-Cope \& Brown, 1992).

Little research is evident regarding how HIV affects the lives of children whose parents have the disease (Desmond \& Gow, 2002). Furthermore, discussions where children themselves speak on social issues have been limited in the academic literature. The next section discusses HIV and AIDS related stigma as experienced by children.

\subsection{Experiences of children on HIV and AIDS Stigma}

Little scientific information exists as to the exact nature and extent of the stigmatisation of children affected by HIV and AIDS in South Africa (Strode \& Grant, 2001). Furthermore, few studies have been conducted where assessments of the HIV status of children were done. It was only in 2003 that Shisana and Simbayi conducted the first assessment of the HIV status of children, which revealed that HIV prevalence was fairly high among South African children under the age of 14. This prevalence, based on the testing of 2350 children aged two to 14 years, was found to be $5.6 \%$. A further report drawing on this data established that among a subset of 1377 children, the HIV prevalence was $6.2 \%$ (Brooks, Shisana \& Richter, 2004).

Research indicates that the stigmatisation of, and discrimination against children affected by HIV and AIDS are characteristics of the HIV and AIDS epidemic in many countries, particularly in developing countries such as South Africa (Richter, 2001). Children who lose their parents to AIDS are often stigmatised or ostracised by their communities. In addition, AIDS-related stigma may linger long after the infected individual has passed away (UNICEF, 1999). Consequently, survivors often try to conceal the true cause of the loved one's death.

In his study on the planning for the care of orphans and HIVIAIDS-affected children, Smart (2003) reported that children affected by HIV and AIDS are believed to be more vulnerable than adults, as they face the possibility of stigma relating to their own status, if they are infected, as well as stigma flowing from their parents or caregivers' status. This stigma often continues even after the death of their parents, when they are rejected or treated with scorn by the extended family and the community.

Strode and Grant (2001), in their research into the role of stigma and discrimination in increasing the vulnerability of children and youth affected by HIV and AIDS, argue that once a person's prejudiced thoughts lead them to doing something, or to omitting to do something that either harms or denies services or entitlements to another person, the act that harms is a discriminatory act. For example, a person may fear a child or youth infected or affected by HIV and AIDS and may perceive them as blameworthy or inferior, and for this reason may be extremely indifferent to their needs.

Research conducted by Stein (2004b) in Khayelitsha, South Africa indicated that HIV-positive mothers often indefinitely delay disclosure of their status to children, on the grounds that their children are too young to understand the nature of HIV and AIDS, and because they believe that disclosure is not in the best interest of their children. Another study in Kwa-Zulu Natal found that children are frequently excluded from discussions about the imminent or recent death of a parent on the grounds that death is not an appropriate topic for children to discuss (Marcus, in Stein 2004b). A study by Rosenheim and Reicher (1985 in Kheswa, 2006) however, found that children who were informed of their parent's terminal illness showed significantly less anxiety than children who were not told. It was also noted that children who were not explicitly told are seldom wholly oblivious to the terminal nature of a parent's condition. To be kept in the dark made 
them feel guilty, anxious, depressed, and isolated (Van Dyk, 2005). By means of informal discussions with South African youth, Stein (2004a) established that children feel betrayed when disclosure occurs immediately prior to illness or to the death of the parent. Few specific studies on children's experiences of stigma have argued that children affected and infected by HIV and AIDS suffer considerable material and psychosocial disadvantage due to HIV-related stigma both directly and indirectly (Deacon \& Stephney, 2007; Strode \& Grant, 2001).

Research indicates that the influence of stigma associated with HIV and AIDS goes beyond individuals infected with HIV (Skinner \& Mfecane 2004). This influence makes children more vulnerable to courtesy stigma relating to their own status, as well as stigma from their parents HIVIAIDS status (Strode \& Grant, 2001), which might result in them experiencing stigma more intensely (Deacon \& Stephney, 2007). In this article, at least four incidences of the stigmatisation which impacted children affected by HIV and AIDS from different contexts are stated: the first incidence of a girl from the East Rand in South Africa who disclosed her mother's HIV and AIDS status to her educators. It was reported that her educators disclosed her status at the assembly, resulted in other children laughing at her. Other children started playing cruelly with her and teased her that his mother had got AIDS (Clacherty \& Associates, 2001).

The second incidence is of children affected by HIVIAIDS who were refused to continue schooling or to be removed from school by their parents; as a result of the stigma they receive (Strode \& Grant, 2001). The third incidence of the late Nkosi Johnson who was refused admission at the age of 7 years old after his mother told the school that he was living with HIV. He also reported incidences of children who greeted him at school but when he went closer to them, they move away (Department of Health, 2000).

Lastly, the incidences of stigmatization are from parents of other children who complained about the presence of children infected or affected by HIVIAIDS in certain pre-schools and crèches (Strode \& Grant, 2001). Lastly, incidence of the AIDS Legal Network in Kwa-Zulu Natal which dealt with a case where a 16-year-old girl was removed by her parents from a private school when the girl's doctor unlawfully told them that their daughter was living with HIVIAIDS (Strode \& Grant, 2001).

It is therefore clear that although some work has been done on South African children's experience of HIV-related stigma, much still remains to be done to gain a full understanding of how they are affected by and live with stigma.

\section{Research Design and Methodology}

This exploratory study aimed to examine the experiences children of HIV and AIDS stigma. Qualitative method of data collection and analysis were employed.

\subsection{Data collection}

\subsubsection{Semi-structured interview}

The data for this article was collected by means of semi-structured interviews conducted with ten children (aged 13 to 16 years) in one of the offices of their organization. Semi-structured interviews were used for the following three primary reasons. Firstly, it allows one to collect large amounts of data quickly (Marshall \& Rossman, 1989). Secondly, the process allows for a wide variety of information and many respondents. It also permits immediate follow-up questions and clarification (Kvale, 1996). Lastly, semi-structured interviews helped the researcher to understand the world from the child respondents' point of view, and to unfold the meaning of their own experiences (Kheswa, 2006). The interview sessions were held with the children on a one-to-one basis and took approximately thirty minutes each. None of the participants in the present study withdrew, and all complied with the above-stated criteria.

\subsubsection{Research respondents}

Respondents consisted of ten children aged between 13 and 16 children (three boys and seven girls) who volunteered to participate in this study. The respondents' details are presented in Table 1. The names of respondents are pseudonyms in order to maintain anonymity. Each respondent was selected for the study on the basis of the following criteria. Firstly, all respondents had received training as peer counsellors on the HIV and AIDS programmes. Secondly, they had all been involved in HIV and AIDS programmes for at least one year and they had all remained involved in the HIV and AIDS activities at a non-profit organisation that provides accessible psychosocial services for children, youth, and families from previously disadvantaged communities in the East Rand, and which served as a gateway for this research. This was to ensure that they would have had sufficient experience to speak with some understanding about the stigmatisation of 
children affected by HIV and AIDS in the neighbourhood where they lived.

Thirdly, the respondents had to be conversant in Isizulu or Southern Sotho. This criterion was largely informed by the fact that Isizulu and Southern Sotho were the most commonly understood languages in the area where the research was conducted. Again, these were the languages in which the primary researcher (the first author) is most proficient. The interviews or sections of interviews that were conducted in isizulu and Southern Sotho were subsequently translated directly into English by a translator, and then back-translated to check the accuracy of the translations. Finally, the respondents had to explicitly indicate an unequivocal willingness to participate in the study (Kruger, 1988). Respondents were informed that they could refuse to answer any questions they wished to, and/or withdraw from the study at any time.

\subsection{Data analysis}

The individual interviews with all ten respondents were tape recorded and transcribed. The data were examined by means of thematic content analysis. Thematic analysis is a method for identifying, analysing and reporting patterns (themes) within data (Braun \& Clarke, 2006). The data were initially encoded into themes, and were clustered under these themes (cf. Neuman, 1997).

\section{Results}

Demographics of the respondents

The respondents' details are presented in Table 1. The names of child respondents are pseudonyms in order to maintain anonymity. As indicated before, three boys and seven girls (between 13 and 16 years) volunteered to participate.

Table 1: Summary of demographic profile of child respondents

\begin{tabular}{|l|c|c|c|c|}
\hline \multicolumn{1}{|c|}{ Names } & Age & Home language & Residential area & Experience (years) \\
\hline 1. S'busiso & 13 & Isizulu & Katlehong & 1 \\
\hline 2. Sandile & 15 & Isizulu & Katlehong & 1 \\
\hline 3. Thabo & 14 & Southern Sotho & Katlehong & 1 \\
\hline 4. S'bongile & 16 & IsiZulu & Vosloorus & 2 \\
\hline 5. Thembisile & 14 & IsiZulu & Thokoza & 1 \\
\hline 6. Nonhlanhla & 16 & Isizulu & Thokoza & 2 \\
\hline 7. Thandi & 13 & Isizulu & Katlehong & 1 \\
\hline 8. Sellwane & 14 & Southern Sotho & Vosloorus & 1 \\
\hline 9. Thandeka & 16 & IsiZulu & Vosloorus & 2 \\
\hline 10. Thokozane & 14 & Isizulu & Thokoza & 1 \\
\hline
\end{tabular}

\subsection{Themes}

Data obtained from the interviews with the children respondents are presented under the following themes and subthemes: expression of misunderstanding of stigmatization; sources of stigmatization; forms of stigma; and the intervention aimed at addressing stigma.

\subsubsection{Expression Of Understanding Of Stigmatisation}

The majority of children managed to speak about and explain aspects of the stigmatisation of children affected by HIV and AIDS. This might also explain why some respondents were at certain points aware of their stigmatising utterances. Some viewed stigmatisation as a negative attitude towards people suffering from AIDS. Furthermore, others perceived stigmatisation as thinking negatively about those children affected by HIV and AIDS and treating them badly.

The following comments were made by those respondents who were aware of stigmatisation and its effects.

It means having a negative attitude against people with AIDS (Thembisile).

Treating people with AIDS negatively (Thandeka; Sellwane)

Stigmatised children are badly treated by the community members. Children think negatively about those children 
affected by HIV and AIDS (S'bongile).

Thinking negatively about HIV positive people (Nonhlanhla)

Few respondents in this study talked about how important it is not to stigmatise, yet at the same time they described how parents of children affected by HIV and AIDS should be institutionalised to avoid the further incidences of stigma. (Thabo)

HIV positive people should be placed in an institutions were they will not be treated badly by community members

Let them be separated from their family members or confined in certain rooms. Maybe that might be a solution to ill treatment (Thokozane)

\subsubsection{Sources Of Stigmatisation}

The following sub-themes were generated from the raw material produced by the child respondents:

\subsubsection{Ignorance and misunderstanding}

The types of stigma reported by most respondents were as a result of the ignorance and misunderstanding. The majority of the respondents expressed the opinion that ignorance and misunderstanding of HIV and AIDS amongst the majority of community members was one of the causes of the stigmatisation of children affected by these conditions.

Lack of knowledge causes the spread of HIV and stigma attached to it (Thabo).

Children think negatively about those children affected by HIV and AIDS, maybe this is because of the lack of knowledge among school children (S'bongile).

The behaviour of parents who do not allow their children to play with others whose parents are HIV positive or ill are the results of such stigmatisation.

\subsubsection{Belief systems}

The current research shows that this kind of stigmatisation persists because it is deeply enmeshed with social and personal beliefs. This is evident in the extract below:

Old people believe that witchcraft is the cause of HIV. This is sometimes confusing to us (Thabo). Many children we're interacting said that their parents who practice witchcraft are able to cure the disease (Thabiso)

AIDS is believed as a punishment from the ancestors and God (Thandeka)

In our community, children are not allowed to play with children of parents, who are HIV positive, fearing that they might have AIDS also (Sandile).

Some families believe that if their children play with children affected by HIV and AIDS, they will be infected (Sellwane).

\subsubsection{Failure to disclose HIV status to their children}

Parents living with HIV struggled to disclose a positive test results to their children. This is consistent with the literature reviewed earlier, data show that the majority of parents do not disclose their HIV status to their children until it has progressed into AIDS (cf. Marcus, in Stein, 2004a).

Parents don't talk about their status to their children (Sandile).

Some children are lied to. Their parents do not talk to them about their illnesses (Thembisile).

Parents believe that disclosure is not in the best interest of their children. The former might also fear being stigmatised. Another reason for non-disclosure might be cultural, since children are frequently excluded from making decisions or from any discussion by their parents about issues related to sex and sexuality.

\subsubsection{Fear}

The data show that community members fear that HIV and AIDS can be transmitted casually to their children.

I sometimes fear to play with them at home (Thandeka).

Some families do not allow their children to play with children from the family where one family member is AIDS ill.

Some don't have access to formal education because of the fear that they can infect others (S'busiso). 
In another family, they believed that playing with children whose brother is infected by HIV would result in their children being infected. They do not allow their children to share their toys with children from the family where the mother is HIV-positive (Nonhlanhla).

I remember one mother hitting her daughter after she found her playing with a child whose mother passed away recently after a long illness (Thabo).

Responses indicated that people not only fear physical contact with people who suffer from HIV and AIDS, but also with children of such people. Such fears of casual transmission result in an immediate stigma. This is evident in the extracts mentioned above.

\subsubsection{Forms Of Stigmatisation}

The following themes related to forms of stigmatisation were generated from the raw data as expressed by the respondents.

\subsubsection{Language/verbal form of stigmatisation}

The following themes related to the language forms of stigmatisation as expressed by the respondents: gossip and teasing by other learners; Labelling and use of derogatory words to describe people living with HIV or AIDS; and the stigmatising utterance.

\subsubsection{Gossip and teasing by other learners}

Consistent with the literature reviewed earlier, the data demonstrate that children affected by HIV and AIDS experience physical and social isolation such as gossip, name-calling or being teased. The present data show that children who are affected by HIV and AIDS are badly treated by other learners in their schools and they also avoid playing with them. This is illustrated by the following remarks by the child respondents:

Children affected by HIV and AIDS receive bad treatment from other learners (Thandeka).

Others avoid playing with them. They don't feel sorry for them (Thembisile).

If your friend is affected by HIV and AIDS, you also get bad treatment (Nonhlanhla).

It's just like they treat them differently, not like a normal person. They just treat them different; they beat them up and don't want to share food with them. Sometimes they don't want anything to do with them (Sellwane).

Learners in school laugh at other children affected by HIV and AIDS. They don't understand that it is not their fault that their parents are ill. Again, the fact that their parents are ill does not mean that they are also ill. They don't understand that AIDS affect all of us (Sandile).

Children affected by HIV and AIDS receive bad treatment from other learners. Others will gossip about them. Some of them had decided to drop out of school (Thabo).

This kind of teasing impacts negatively on children affected by HIV and AIDS because it also affects their sense of self-worth. The present study indicates that affected children would prefer not to attend school rather than be mocked or stigmatised by their peers. This is also evident in the extracts below:

Another boy who used to participate actively in class is no more participating because other children are teasing him about his brother who is HIV-positive (Sandile).

Another child whose parents were living with HIV and AIDS has dropped out of school because other learners teased him (Thabo).

Labelling and use of derogatory words to describe people living with HIV or AIDS

The data demonstrate that learners use terms with negative connotations whenever they are talking about children affected by HIV and AIDS. They use hurtful words, which are a powerful means to stigmatise. This is evident in the following extracts:

Others give the names like 'three letters' or 'children of three letters' and 'biltong' (S'bongile).

Another learner in our class reported the case of a learner who said that he is Z3.

Our class teacher was not aware of the meaning of that and other children explained it to her, and she punished that learner (Sandile).

When children affected by HIV and AIDS are passing by, other children will raise three fingers without saying anything. This will mean that they are affected (Thandeka). 
The term Z3 in the first quotation above is essentially a vulgarization of the acronym, AZT. This refers to the AZT treatment received by people who are ill with AIDS. The three fingers sign is generally employed to refer to the three letter acronym, HIV. 'Biltong' as used by S'bongile is a reference to the reported darkening of AIDS suffers' skin colour and to the loss of weight associated with HIV and AIDS (Kheswa, 2006). The research conducted in the Kwa-Zulu Natal community reported similar results (Swaan, 2008).

Stigmatising utterance

The present research showed that stigma concerning HIV and AIDS persists because some respondents were at certain points unaware of their stigmatising utterances. Some respondents talked about how important it is not to stigmatise, yet at the same time they described how children affected by HIV and AIDS should be institutionalised to avoid the further spread of the condition.

I sometimes fear to play with them at home (Thandeka).

If you get HIV, you are dead. Remember that it does not have any treatment (Thembisile).

The government should build more centres where children affected by HIV and AIDS will be kept to avoid further spread of AIDS (Thabo).

\subsubsection{Social stigma}

The following themes related to the social forms of stigmatisation as expressed by the respondents: rejection by extended family members and the exclusion and isolation by community members.

\subsubsection{Rejection by extended family members}

Not much was said about family members stigmatising children affected by HIV and AIDS. As is corroborated by the literature reviewed earlier, the data likewise indicated that children affected by these conditions are rejected by their extended family members. These results in their relatives cutting themselves off from these extended family members because of their fears that they may be stigmatised.

There is a family in our area where both parents died of AIDS, leaving three children of 16, 9 and 5 years alone. They are presently staying alone. Even their aunt who was supportive before never paid them a visit since the death of their parent (Thembisile).

\subsubsection{Exclusion and isolation by community members}

The present study demonstrates that children affected by HIV and AIDS are isolated by community members. Social isolation usually manifests itself as the reduction of social interaction with other children. The following child respondents describe social isolation as follows:

Some families do not allow their children to play with children from the family where one family member is AIDS ill (Thandeka).

Playing with children whose brother is infected by HIV will result in their children infected (Thabo).

Other families do not allow their members to share toys with children whose family member is HIV positive. In turn they choose not to play with them (Nonhlanhla).

Another child was expelled from school because of her positive status (S'bongile).

Another one was excluded from football team (Thabo).

The reason why parents do not allow their children to play with others whose parents are infected with HIV or ill with AIDS might be associated with their fear that their children might become infected or that their association with people affected by HIV and AIDS could result in their own stigmatisation.

\subsubsection{Intervention Aimed At Addressing Stigma}

The majority of the respondents identified the following as intervention strategies for addressing stigmatisation: compulsory HIV and AIDS education; early disclosure and finding cure for AIDS.

\subsubsection{Compulsory HIV and AIDS education}

Majority of the respondents recognised the role of limited knowledge in causing stigma. They believed that educating 
community members about HIV and AIDS could reduce the problem.

Compulsory HIV and AIDS education for all community members (Thabo)

HIV and AIDS education to be compulsory in all schools (Thandi \& Sandile)

AIDS education be part of curriculum in all levels of education, from primary schools to tertiary S'busiso)

Teaching family members about the basic information on HIV and AIDS could reduce stigma (Thembisile).

\subsubsection{Early disclosure}

A related and extremely important consequence of stigma is its effect on people's ability and willingness to disclose a positive result to others (Ogden \& Nyblade, 2005). Participants in this study argued that early disclosure of one's HIV positive status contribute to reduction of stigma.

People diagnosed with HIV and AIDS must disclose their status. That help the to receive treatment in the early stages of their disease (Nonhlanhla)

\subsubsection{Finding cure for AIDS}

Some of the participants argued that stigma among children affected by HIV and AIDS could be reduced by finding cure for AIDS. The following child respondents describe social isolation as follows:

Stigma can only be reduced if a cure for AIDS can be found (Sibongile)

This proposed intervention's reliance on the world of medicine to eliminate stigmatization is of course somewhat limiting (Robert 2006).

\section{Discussion of Results}

The data obtained show that most respondents were affected by the direct stigma which leads to active discrimination of children affected by HIV and AIDS. This is courtesy stigma which is attached to people because of their association with HIV and AIDS. This was evident when some of the children of parents who suffered from HIV and AIDS were rejected, excluded and isolated by community members. Direct effects occurs when stigma affect children when it leads to active discrimination or status loss (which can exacerbate existing social marginalisation).

The majority of children managed to speak about and explain aspects of the stigmatisation of children affected by HIV and AIDS. This might also explain why some respondents were at certain points aware of their stigmatising utterances. Few respondents in this study talked about how important it is not to stigmatise, yet at the same time they described how children affected by HIV and AIDS should be institutionalised to avoid the further spread of their conditions. This is consistent with the findings by Deacon and Stephney, (2007) on self-stigmatisation which is associated with stigmatised people's responses to stigma which include self-stigmatisation.

Consistent with the findings of earlier studies (Crawford et al., 1992, Kheswa \& Duncan, 2011), the data demonstrate that the respondents perceived the lack of knowledge of HIV and AIDS amongst the majority of community members as a cause of the stigmatisation against children affected by this pandemic. Research results derived from the respondents showed that an incorrect understanding of HIV and AIDS among community members fuels the stigmatisation of children whose parents are ill with AIDS or have died of AIDS. This is evident in incidents where children whose parents are HIV- positive were often presumed to suffer from HIV and, therefore, are isolated. Consequently, people tend to distance themselves from those who are infected and/or those who are associated with HIV-positive persons. This is consistent with previous studies which indicated that the stigmatisation and discrimination with which people affected with HIV often live are transferred to their children, making their fight for survival much more precarious (UNICEF, 1999; Crawford, 1996). In addition, research has also revealed that AIDS-related stigma may linger, even after the infected parents have passed away which is consistent with what Crawford (1996) found. Respondents recognised the role of limited knowledge in perpetuating stigma, and held that acquiring more detailed knowledge about HIV and AIDS could reduce stigma.

The present research also points to common views being held by respondents that stigmatisation of children affected by HIV and AIDS persists because of the belief systems (Strode \& Grant, 2001) and fears surrounding physical contact and transmission, which is consistent to the research conducted by Strode \& Grant, (2001). Incomplete and contradictory knowledge of HIV reinforces some of those beliefs and contributes to the related stigma.

Responses showed that the respondents considered that the majority of parents do not disclose or delay disclosure of their HIV status to their children until it has progressed into AIDS, fearing to be stigmatised. This is 
consistent with the findings of the literature reviewed (Stein, 2004) that some children are lied to or are not told about the cause of their parents' illness or death. This was also confirmed by another study in Kwa-Zulu Natal, which found that children are frequently excluded from discussions about the imminent or recent death of a parent, on the grounds that death is not an appropriate topic for children to discuss (Strode \& Grant, 2001). This conspiracy of silence is believed to be one of the causes of the experience of stigmatisation among children affected by this pandemic.

As with the literature reviewed previously, the data obtained from the adult respondents indicated that AIDS is commonly viewed as a witchcraft and punishment from the ancestors and God. Similarly, the data also suggested that the belief that HIV and AIDS constitute a punishment from the ancestors also increases the level of stigmatisation against children affected by the pandemic. Some HIVIAIDS caregiver respondents argued that some people believe that the ancestors can punish family members by sending illness and misfortune if they are not honoured and this can also contribute to stigmatisation.

From the data it is evident that some respondents believed that HIV can be casually transmitted to children. Community members are reported to experience such fears. People fear not only physical contact with sufferers who have HIV and AIDS, but fear contact with everything connected to such persons. Such fears of casual transmission result in immediate stigmatisation. This was evident in research conducted by Kok et al., (1998) that indicated that anger and fear contribute to the development of stigmatisation and discrimination both on the part of those who are HIV-positive and those who are HIV -negative.

The data from the respondents provide much information about stigmatisation by educators, indicated such behaviour occurring among teachers in crèches and pre-schools. Some respondents however, reported educators as offering comfort, care and support to children affected by these conditions. Some respondents mentioned incidents where educators referred such learners to organisations offering care and support.

The inaccessibility of formal education was reported to stem from the climate of fear that still surrounded the disease. Young children whose parents had died of AIDS reported a great deal of resistance from parents when they attempted to enrol these children in local pre-schools.

The data from the respondents indicated that extended families and friends reject children affected by the pandemic. Responses show the diminishing care provided by the relatives of a person living with HIV. The relatives, who started providing care, support and food, ceased to do so after they discovered that the family member is HIV-positive or has died of AIDS. These results are consistent with the literature reviewed earlier (Crawford, 1996; Richter, 2001). It is likely that relatives' negative attitude towards those affected children results from a fear that relatives might also be infected if the latter continue to interact with children.

The data obtained from the respondents show that children affected by HIV and AIDS experience exclusion and social isolation, which usually manifests itself as the reduction of social interaction with other children. The reason why parents do not allow their children to play with others whose parents are infected with HIV or ill with AIDS might be associated with their fear that their children might be infected or that being associated with people affected by HIV and AIDS could result in their own stigmatisation.

Respondents also reflected that community members use terms with negative connotations whenever they are talking about children affected by HIV and AIDS. They employ words that hurt, which are a powerful means of stigmatisation. Terms with negative connotations are part of daily conversation and are used in gossip. Common terms to describe children whose parents live with HIV and AIDS include the following: Z3, biltong, three letters and raising three fingers without saying anything. The 'three letters' label refers to the three letter abbreviation, HIV. Biltong refers to the darkening of skin colour, and to the loss of weight common among people with HIV and AIDS. Z3 referred to the AZT treatment received by AIDS sufferers. Adult respondents indicate that families are stigmatised if certain family members suffer from these conditions. Children and their parents are held responsible for the HIV status of family members.

Respondents believed that community members know how HIV is transmitted, but that more knowledge of other aspects of HIV and AIDS is inadequate. Furthermore, the majority of respondents strongly held that promoting a deeper understanding of HIV and AIDS would reduce the stigmatisation of children affected by HIV and AIDS. Respondents recognised the role of limited knowledge in causing stigma. Therefore, they believed that acquiring more detailed knowledge about HIV and AIDS could reduce such stigma. Data acquired from the respondents indicated that compulsory HIV and AIDS education in schools could also reduce such stigma.

\section{Limitations}

Some important data might have gone missing, owing to either a lack of clear understanding of the concept of stigmatisation amongst some child participants and a few caregivers. As little research has been carried out into the 
stigmatisation of children affected by HIV and AIDS in South Africa, little is presently known. Thus, literature and results stemming from the Western world had to be relied upon and applied to South Africa. It is hoped that this research will contribute to fill the gap in local research to some degree.

The present research acknowledges that the interview process might have been influenced by the researcher's appearance, tone of voice, wording of questions and his expectations about the participants' answers, based on their appearance and their living conditions.

The researcher maintains that the use of a tape recorder allowed him to make a full record of each interview without being distracted by detailed note taking. However, this could have detracted from the intimacy of the encounter, with both the researcher and the participants in part performing for the tape-recorder rather than really talking to each other, thus influencing the research results.

\section{Conclusion}

This article has provided some important insights into the experiences of stigmatization of children affected by HIV and AIDS. It has shown that stigmatization among these children as wide-ranging and pervasive that they frequently opt for social invisibility and isolation. The results indicate that the research respondents largely favour interventions aimed at changing communities' understanding of the causes and genesis of HIV and AIDS as a means of combating HIV and AIDS-related stigmatisation. Furthermore, the article also explored possible interventions aimed at addressing the invidious position of these children suggested by the research respondents. This is consistent with the dominant forms of intervention aimed at addressing the stigmatisation associated with HIV and AIDS, salient findings of this study is that many respondents largely favour interventions aimed at changing communities' understanding of the causes and genesis of HIV and AIDS as a means of combating HIV and AIDS-related stigmatisation.

This article acknowledges the fact that some important data might have gone missing, owing to either a lack of clear understanding of the concept of stigmatisation amongst some child participants and a few caregivers.

This article recommends that more research be conducted on how HIV stigma affects the lives of children whose parents are affected by HIV and AIDS in South Africa. This will create an opportunity for children to speak on social issues which are limited in the academic literature. The article succeeded viewing children as social agents capable of participating in research and contributing to our understanding of HIV and AIDS.

\section{References}

Avert. (2010). HIV and AIDS in South Africa.[Online] Available from: http://www.avert.org/aidssouthafrica (Accessed on 14 February 2010).

Bandstra N F, Camfield, CS, \& Camfield PR. (2008). Stigma of Epilepsy. The Canadian Journal of Neurological Science, 35 (4): 436440.

Behuniak, S.M. (2011). The living dead? The construction of people with Alzheimer's disease as zombies. Ageing \& Society 31, 2011, 70-92.

Bor, R. J. \& Elford, J. (1998). The family and HIV today: Recent research and practice. London: Cassell.

Braun, V \& Clarke, V. (2006). Using thematic analysis in psychology. Qualitative Research in Psychology, 3: 77-101.

Bresnahan, M \& Zhuang, J. (2011). Exploration and Validation of the Dimensions of Stigma. Journal of Health Psychology. 16(3) 421429.

Brooks, H., Shisana, O. \& Richter, L. (2004). The national household HIV prevalence and risk survey of South African children. Cape Town: HSRC Publishers.

Clacherty \& Associates (2001). The role of stigma and discrimination in increasing the vulnerability of children and youth affected by HIVIAIDS. Research conducted by Save the Children (UK), pp. 25-37.

Cluver, L \& Orkin, M. (2009). Cumulative risk and AIDS-orphan-hood: Interactions of stigma, bullying and poverty on child mental health in South Africa. Social Science \& Medicine, 69:1186-1193.

Crandall, C. S. \& Moriarty, D. (1995). Physical illness, stigma and social rejection. British Journal of Social Psychology, 34, 67-83.

Crawford, I., Allison, K., Robinson, W., Hughes, D. \& Samaryk, M. (1992). Attitudes of American Baptist ministers toward AIDS. Journal of Community Psychology, 20(4), 304-308.

Crawford, I., Humfleet, G., Ribordy, S., Ho, F. \& Vickers, V. (1991). Stigmatisation of AIDS patients by mental health professionals Psychology: Research and Practice, 22, 357-361.

Crewe, M. (1992). AIDS in South Africa: The myth and the reality. London: Penguin.

Deacon, H. \& Stephney, I. (2007). HIV/AIDS, stigma and children: a literature review. Cape Town: HSRC Press.

Deacon, H., Stephney, I. \& Prosalendis, S. 2005. Understanding HIV/AIDS stigma: a theoretical and methodological analysis. Cape Town: HSRC Press.

Department of Health and Human Services (2004). HIVIAIDS stigma. Health Resources and Services Administration. The Body: The 
complete HIVIAIDS resource, August 2003. 1-12.

Department of Health. (2000). National HIV and Syphilis antenatal sero-prevalence survey in South Africa. Pretoria: Department of Health.

Emlet C.A. (2005). Measuring stigma in older and younger adults with HIVIAIDS: An analysis of an HIV stigma scale and initial exploration of subscales. Research on Social Work Practice 15(4): 291-300.

Germann, S. (2004). Psychosocial Impact of HIVIAIDS on children. AIDS Analysis Africa, 2(13), 18-20.

Goffman, E. (1963). Notes on the management of spoiled Identity. Englewood Cliff: Prentice-Hall.

Herek, G.M. (1999). Illness, stigma, and AIDS. In P. Costa, Jr. \& G. Vanden-Boss (Eds), Psychological aspects of serious illness: Chronic conditions, fatal diseases, and clinical care. (p.74-82). Washington: American Psychological Association.

Herek, G. M. \& Capitanio, J. P. (1993). Public reactions to AIDS in the United States: A second decade of stigma. American Journal of Public Health, 83, 574-577.

Herek, G \& Glunt, E. (1988). An epidemic of stigma: public reaction to AIDS. American Psychologist, 43(11), 886-891.

Janni J. Kinsler, Mitchell D. Wong, Jennifer N. Sayles, Cynthia Davis, and William E. Cunningham. (2007). The Effect of Perceived Stigma from a Health Care Provider on Access to Care Among a Low-Income HIV-Positive Population. AIDS Patient Care and STDs. 21(8): 584-592.

Johnson, S. (1995). Model of factors related to tendencies to discriminate against people with people with AIDS. Psychological Reports, 76(2), 563-572.

Jones, E. E., Farina, A, Hastorf, A. H., Markus, H., Millwer, D. T, \& Scott, R. A. (1984). Social stigma: The psychology of marked relationships: New York: W.H. Freeman and Company.

Kheswa, G.E. (2006). 'Stigmatisation of children affected and infected by HIV and AIDS in KATHORUS townships', Unpublished MA (Counselling Psychology) research report, University of the Witwatersrand, Johannesburg.

Kheswa, G \& Duncan, N. (2011). The stigmatization of children affected by HIV and AIDS IN A Gauteng township area. Child Abuse Research: A South African Journal, 12 (1): 38-50.

Kok, G., Kolker, L., de Vroome, E. \& Dijker, A. (1998). Safe sex and compassion: Public campaigns on AIDS in the Netherlands. In T. Sandfort (Eds), The Dutch response to HIV: Pragmatism and consensus (pp. 19-39). London: UCT Press.

Kruger, D. (1988). An introduction to phenomenological psychology. Cape Town: Juta \& Co.

Kvale, S. (1996). Interviews: an introduction to qualitative research interviewing. California: Sage Publications.

Mak, W.W.S., Cheung, R.Y.M., Law, R.W., Woo, J., Li, P.C.K. \&Chung, R.W.Y. (2007). Examining attributional model of self-stigma in social support and psychological well-being among people with HIVIAIDS. Social Science \& Medicine 64(8): 1549-1559.

Marshall, C. \& Rossman, G. B. (1989). Designing qualitative research. London: Sage Publication.

Mason, T., Carlisle, C. Watkins, C. \& Whitehead, E. (2001). Stigma and social exclusion in healthcare. London: Routledge.

Mawar, N., Sahay, S., Pandit, A., \& Mahajan, U. (2005). The third phase of HIV pandemic: Social consequences of HIV IAIDS stigma \& discrimination \& future needs. Indian Journal Medical Research, December, pp 471-484.

Miller, K. \& Mastrantonis, H. (1992). AIDS in the workplace: White collar employees' perceptions. Paper presented at the 10th Annual Congress of the Psychological Association of South Africa, Stellenbosch.

Neuman, W.L. (1997). Social research methods: Qualitative and quantitative approaches (2nd Ed). Boston: Allyn \& Bacon.

Ogden, J \& Nyblade, L (2005). Common at its core: HIV-Related Stigma across contexts. International Centre for Research on Women (ICRW).

Powell-Cope, G. M. \& Brown, M. A. (1992). Caring for a loved one with AIDS: The experiences of families, lovers, and friends. Seattle: University of Washington.

Puhl, R.M., Schwartz, M.B. \& Brownell, K.D. (2005). Impact of perceived consensus on stereotypes about obese people: A new approach. Health Psychology 24(5): 517-525.

Richter, M. (2001). Nature and extent of discrimination against PLWAs in South Africa: Interviews and a study of AIDS Law Project client file 1993-2001. Johannesburg: University of the Witwatersrand AIDS Law Project, Centre for Applied Legal Studies: 1-46.

Roberts, SJ, (2006). Countering stigma: Collectively counselling and AIDS identity. In P. Alexander, M. Dawson \& M. Ichharam (Eds.). Globalisation \& new identities: A view from the middle (pp. 171-190). Johannesburg: Jacana Press.

Rosenheim, E. \& Reicher, R. (1985). Informing children about a parent's terminal illness. Journal of Child Psychology and Psychiatry, 26, 995-998.

Shisana, O. \& Simbayi, L. (2003). Nelson Mandela/HSRC study of HIVIAIDS: South African national HIV prevalence, behavioural risks and mass media, household survey. Cape Town: HSRC Press.

Sibitz, I., Unger, A., Woppmann, A., Zidek, T \& Amering, M. (2011). Stigma

Resistance in Patients With Schizophrenia. Schizophr Bull (2011) 37 (2): 316-323.

Simbayi, L.C., Kalichman, S., Strebel, A., Cloete, A., Hendaa, N. and Meketoa, A. (2007). Internalized stigma, discrimination, and depression among men and women living with HIVIAIDS in Cape Town, South Africa. Social Science \& Medicine 64(9): 18231831.

Skinner, D. \& Mfecane, S. (2004). Stigma, discrimination and the implications for people living with HIVIAIDS in South Africa. Journal of social aspects of HIV/AIDS. 1(3):157-164.

Smart, R. (2003). Planning for orphans and HIVIAIDS affected children. In L. Uys \& S. Cameroon (Eds), Home-based HIVIAIDS care. (pp. 174 -191). Cape Town: Oxford University Press.

Stein, J. (2004a). HIVIAIDS and the culture of silence: Disclosure to children. AIDS Bulletin, 13(1), 15-19. 
Stein, J. (2004b). Orphans of the hills. Streets as school and home to orphans in the Transkei. AIDS Analysis Africa, 13(2), 42-45.

Streak, B. (2001a), 2 November. HIV positive kids must go to school. Cape Argus. p. 9.

Streak, B. (2001b), 26 October - 1 November. They don't love you like before. Mail and Guardian. p. 13.

Strebel, A. \& Perkel, A. (1991). ' Not our problem' : AIDS knowledge, attitudes, practices and psychological factors at UWC. Psychology Resource Centre Occasional Papers Series, No. 4. Bellville: University of the Western Cape.

Strode A. \& Grant, K. B. (2001). The role of stigma and discrimination in increasing the vulnerability of children and youth infected with and affected by HIVIAIDS. London: Save the Children.

Swaans, K. (2008). Transcending boundaries. Interactive learning learning and action at the interface of HIVIAIDS and agriculture. PhD thesis, Vrije Universiteit, Amsterdam.

UNAIDS/WHO. (2004). AIDS Epidemic Update. Geneva: UNAIDS.

UNICEF (1999). Children orphaned by AIDS: Frontline responses from Eastern and South Africa: Geneva: UNICEF.

Van Dyk, A. (2005). HIVIAIDS and counselling: A multidisciplinary approach. Cape Town: Pearson Education. 